\title{
Causes and Economic Effects of Mortality in Livestock Guarding Dogs
}

\author{
JAY R. LORENZ, RAYMOND P. COPPINGER, AND MICHAEL R. SUTHERLAND
}

\begin{abstract}
We assessed causes of pre-senile mortality among working guarding dogs, and its effects on their management and cost. A population of 449 livestock guarding dogs in 31 states showed no differences in mortality due to breed or sex, but dogs working on open rangelands died more frequently $(p<.001)$ than those working on farms or fenced ranches. Half of the farm dogs died before they reached 38 months of age, by which time nearly three-quarters of the open rangelands dogs had succumbed. Accidents accounted for over half the deaths, culling for inappropriate behavior accounted for one-third, and diseases for $9 \%$. High accident and culling rates in young dogs substantially increased the cost of this predator control technique. However, we found 2 main areas where corrective measures can be applied: (1) increasing the awareness among producers that accidents are a main cause of deaths especially during the dogs' first $\mathbf{3 0}$ months of age; and (2) reducing the number of culls by improving the genetics of the dogs and by training producers to manage them.
\end{abstract}

Eurasian livestock guarding dogs (Canis familiaris) can reduce or eliminate predation on sheep (Ovis aries) and goats (Capra hireus) on farms and ranches in the United States (Coppinger et al. $1983 a, b ;$ Green and Woodruff 1983a). Such reduction depends on dogs being attentive and trustworthy. Dogs deficient in either of those attributes are unsuccessful.

Methods of predator control must be economical to be useful. Although guarding dogs are proving to be of reasonable cost, producers need to be aware of factors that can rapidly change the economic picture. Green et al. (1984) estimated dollar costs of guarding dogs and suggested that ability to deter predators and longevity are additional factors that influence costs relative to benefit.

We examined the effect of ability and longevity on working guarding dogs. Specifically, we looked at: (1) the duration of guarding behavior, which is partially dependent upon the life span of the dog, and (2) the percentage of dogs that show appropriate guarding behavior. The longer a dog lives, the more cost-effective it will become, because the costs of purchase and training can be amortized over a longer period. Moreover, a longer life span makes the generally ineffective juvenile months a smaller percentage of the total.

We assessed causes of pre-senile mortality among working guarding dogs, and its effects on their management and cost. In addition, we developed actuarial statistics that will assist producers, researchers, veterinarians, and breeders in keeping track of the age structure of a population of working guardians, and in planning for replacement animals.

\footnotetext{
Authors are extension specialist, Oregon State University, Corvallis 97331; professor of biology, Hampshire College, Amherst MA 01002; and associate professor of statistics, University of Massachusetts, Amherst 01003. Reprint requests should be sent to Coppinger.

The Geraldine Rockefeller Dodge Foundation provided funding toward the understanding and improvement of guarding dogs in the U.S. Funding for establishment, maintenance, and research at Hampshire College of the Livestock Dog Project was provided by the Rockefeller Brothers Fund, the U.S. Department of Agriculture (USDA/SEA \#59-2259-0-2-119-0), the U.S. Department of Interior (FWS 14-160009-84-924), and Control Data Corporation to Dr. Coppinger. The college contributed financial and administrative support, plus kennel and pasture space. The Anatolian Shepherd Dog Club of Alpine, California, supported the acquisition of dogs from Turkey. We appreciate the informative reports from or cooperating sheep producers and their time spent working with the dogs. The Statistical Consulting Center and the Academic Computing Center at the University of Massachusetts provided assistance in data analysis; other technical assistance was provided by Lorna Coppinger.

Manuscript accepted 4 November 1985.
}

\section{Materials and Methods}

We observed mortality of a population of 449 dogs (80 litters). Our sample represented the total population of livestock guarding dogs placed during 1978-1983 on cooperating farms and ranches under the auspices of Hampshire College's Livestock Dog Project. They were offspring of imported working dogs from Europe and Asia Minor: 120 Turkish Anatolian Shepherd Dogs, 74 Yugoslavian Shar Planinetz, 56 Italian Maremmas, 12 Portuguese Castro Laboreiros, and 183 crosses between the above breeds. Four Tibetan Mastiffs donated by breeders were also included. Pups were born between April 1978 and December 1983. Their ages ranged from 7 to 72 months.

Pups were born and raised with sheep at Hampshire College, at Coppinger's farm, or in several cases on cooperating farms, remaining there for 6 to 12 weeks until they were placed with sheep producers. Two hundred and sixty producers in 31 states participated. All cooperators were volunteers; all had commercial flocks. They raised sheep under 3 different systems of management: (1) ranch (open range with flocks usually greater than 750 ewes with or without continuous shepherding); (2) farm (fenced pastures with more than 15 ewes); and (3) farm/ ranch (large fenced pastures of a section or more or a combination of fenced pasture and open range, supporting usually over 500 sheep). Producers were given written and verbal instructions on care and training of their dogs. We encouraged them to telephone us to discuss any problems.

We defined mortality as the end of a dog's activity as a livestock guardian, for any reason. Pre-weaning mortality was not included in the mortality count. Causes of death were categorized as:

a) accident: unintentional loss of a healthy dog, usually traumatic, but including dogs missing for unknown reasons;

b) cull: a dog removed due to lack of attentiveness or trustworthiness;

c) disease: a fatal health problem (pathogenic, parasitic or congenital), whether it was preventable or not.

Composite life tables and survivorship curves were calculated on age-specific data using the Life Tables and Survivor Functions program (BMDP1L; Dixon and Brown 1979). Typically, life tables and survivorship curves are calculated using the total number of individuals living to each age interval. We used 6-month age intervals; the mortality in each interval was computed as the ratio of the number of dogs that died in the interval divided by the number alive at the beginning of the interval. Survivorship was expressed in terms of a cohort of 1,000 dogs.

\section{Results and Discussion}

\section{Mortality}

During the 6 years of this study, 216 of 449 dogs were lost. Accidents and culling were the predominant causes of mortality. Although livestock management influenced mortality $(p<.001$; Table 1), breed and sex did not.

Survivorship curves (Fig. 1) for working guarding dogs resembled those of wild animal populations with high mortality in the early years. The semi-annual mortality rate was $13 \%$ before 30 months of age and about $5 \%$ thereafter. Age of death in this study was overwhelmingly a product of accidents and culling, with disease (especially age-or breed-related diseases) having virtually no effect on population structure. Most studies on longevity in dogs have been done on kennel dogs where accidents and culling were rare 
Table 1. Causes of mortality of 449 livestock guarding dogs born 1978-1982, by type of management system.

\begin{tabular}{lcccccc}
\hline \hline Management system & Sample size & Accident & Cull & Disease & Total dead & $\begin{array}{c}\text { Percent of } \\
\text { total dead }\end{array}$ \\
\hline Farm & 224 & 48 & 41 & 11 & 100 & .41 \\
Farm/Ranch & 122 & 33 & 18 & 4 & 55 & .45 \\
Ranch & 83 & 43 & 13 & 5 & $61^{*}$ & $.73^{*}$ \\
$\quad$ Total & 449 & 124 & 72 & 20 & 216 & .48 \\
\hline
\end{tabular}

$* p<.001$

(Comfort 1956, 1960), or have been specifically concerned with susceptibility of breeds to disease. Therefore it is not known if the dogs in our particular sample are generally representative of domestic dogs. Bronson's (1982) study of necropsy data on 56 breeds and crossbreeds showed a variation in mean age of death from 3.0 to 9.9 years. Comfort (1960) reported that mastiffs and wolfhounds lived considerably shorter (means of 6 and 7 years, respectively) than spaniels and Pekinese (11 and 12 years). The survivorship curve for guarding dogs on farms and farm/ranches fell in between the curves for kennel dogs given by Comfort (1960) and for a population of stray dogs in Baltimore (Beck 1973).

\section{Management}

Mortality on ranches exceeded mortality on farms and farm/ranches (Breslow Test, $p<.001 ;$ Fig. 1). Because mortality rates

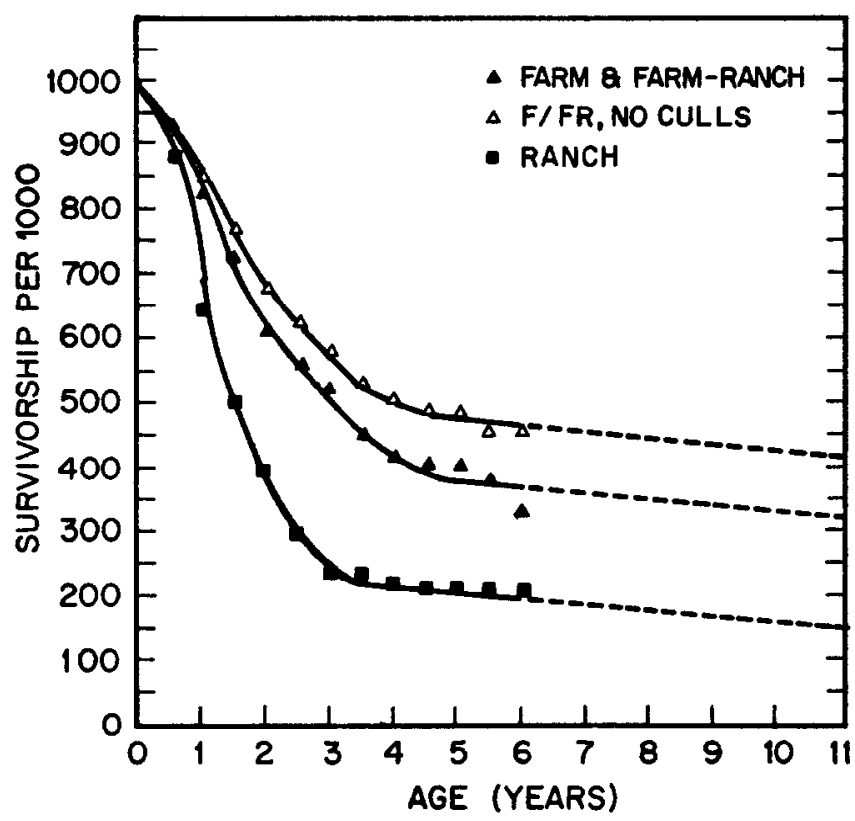

Fig. 1. Survivorship of livestock guarding dogs.

were virtually identical on farms and farm/ranches, these data were combined for comparison with ranches. The semi-annual mortality rate for the first $\mathbf{3 0}$ months was twice as high on ranches (22\%) as on farms and farm/ranches (11\%). However, after 30 months of age, dog mortality was similar in all systems of management.

On ranches, $50 \%$ of the dogs were dead by 18 months of age, compared with 38 months on farms and farm/ranches. Survivorship on ranches slightly exceeded that of stray dogs in an urban environment (Beck 1973). In fact, barely half of the dogs reached working age (about 12 months). The lack of human support in remote areas may have contributed to early deaths, but we suspected a correlation between the high rate of accidents between 6 and 30 months and the occurrence of behavioral problems such as hyperactivity, untrustworthiness and inattentiveness (Coppinger and Coppinger 1980, Coppinger et al. 1983b). High frequencies of investigatory and play behavior associated with development of puppies and with migratory range flocks may have resulted in higher accidental losses. These losses were particularly severe among inattentive dogs. On farms, producers tended to cull untrustworthy dogs, but not inattentive ones. On the range, inattentive dogs were more likely to become lost or killed.

In all management systems the semi-annual death rate decreased to about $5 \%$ after 30 months, indicating that survivors had learned to avoid dangers, or ontogenetic changes had occurred that reduced the likelihood of accidents, or behavioral misfits had been eliminated.

\section{Accidents}

We noted several causes of accidental deaths: 40 dogs $(32 \%)$ disappeared; $38(31 \%)$ were hit by vehicles; $17(14 \%)$ were maliciously shot; $11(9 \%)$ were poisoned; and $18(15 \%)$ were lost to other causes. Half of the deaths of dogs placed on ranches were accidental, compared with $27 \%$ on farm/ranches and $19 \%$ on farms. We suspected that dogs that disappeared or were poisoned were often victims of other forms of predator control (trapping, gunning, or poisoning). Dogs were sometimes shot because friends or neighbors were not aware that the dog was supposed to be with the sheep. Guarding dogs tended not to chase cars; most of the vehicle deaths occurred in young dogs in the farmyard. Dogs hit by vehicles or lost were often displaying inattentive behavior and might otherwise have been culled later. Eighty-six percent of accidental deaths occurred before age 30 months.

\section{Culling}

Of the 72 dogs that were culled, $44(57 \%)$ had injured or killed livestock, $8(11 \%)$ were inattentive to livestock, $5(7 \%)$ bit people, and $5(7 \%)$ were culled for a combination of reasons. Culling accounted for one-third of all deaths. Ninety percent of culling occurred before age 30 months. On farms and farm/ranches, culling reduced the age at which half the dogs were dead (from 52 months to 38 months). However, ranchers tended to cull more heavily than did farmers; $37 \%$ of culled dogs were on ranches, $22 \%$ on farms and farm ranches. Inspection of the data indicated no differences due to breed or sex.

Noxious behaviors appeared to have both genetic and environmental components. Seven litters out of the 80 accounted for one-third of the culls. Several notable cases involved similarities in unacceptable behavior among littermates that had been placed during infancy in geographically separate areas. Also, the offspring of one sire bred to four dams (producing 5 litters) had a cull rate of 2.5 times greater than the average.

Further study of management techniques and early guardian behavior, with a goal of increasing both trustworthy and attentive behavior, should help to identify breeding and training methods that will lead to reductions in culling. For example, untrustworthy dogs often exhibited a high frequency of play behavior, and were often noted to be overfed and overweight. This disposition for "extra" play may be reflective of a diet too high in calories (MullerSchwarze et al. 1982). Also, the work of several investigators 
suggests that the ability to form cross-species social attachments is an inherent ability of all dogs (Cairns 1966, Tomlinson and Price 1980, Black 1981). The species to which a dog forms an attachment and the strength of that attachment is partly dependent on social contacts during critical developmental stages (Scott and Fuller 1965).

\section{Disease}

Disease had minor influence on survivorship. Only 20 dogs died of disease. Two were known victims of heartworm while 4 others died of complications due to intestinal parasites. Two young dogs died of parvovirus and 21 -year-old dogs died of heat stroke. One dog had a persistent urinary infection and was destroyed; one was diagnosed as having San Joaquin Valley Fever; one had a rare blood bacteria; the rest were undiagnosed.

Disease problems likely will increase as the population reaches senescence, but at the present mortality rate, few dogs will reach old age. Whether senescence and the end of working life are coincident is yet unknown. It seems reasonable to expect a 10-year working life.

\section{Economic Effect of Early Mortality}

Early death reduced the effectiveness of these dogs and raised their cost substantially. The cost of a dog includes purchase price, transportation, feeding, veterinary care and all other expenses incurred during its life. The benefit of the dog is in the number of livestock saved during its lifetime. Black (1981) suggested that the use of mongrel dogs would reduce acquisition costs. However, Fig. 2 illustrates that such costs are minor relative to costs of yearly maintenance. Presently, purchase price of a Eurasian guarding dogs equals cost of 1 or 2 years of maintenance. Purchase price substantially influences net cost of the dog only if it dies prematurely. Not only does an early mortality exaggerate the purchase price but it sharply decreases the benefit of the dog.

The cost per working year of a dog was computed with the formula:

$$
\frac{P+A C}{A-1}
$$

where $\mathbf{P}=$ purchase price plus any additional first year costs such as transportation, health certificates, immunizations;

$A=$ age of $\operatorname{dog}$ (A-1 accounts for the essentially ineffective puppy year);

$\mathrm{C}=$ average annual cost.

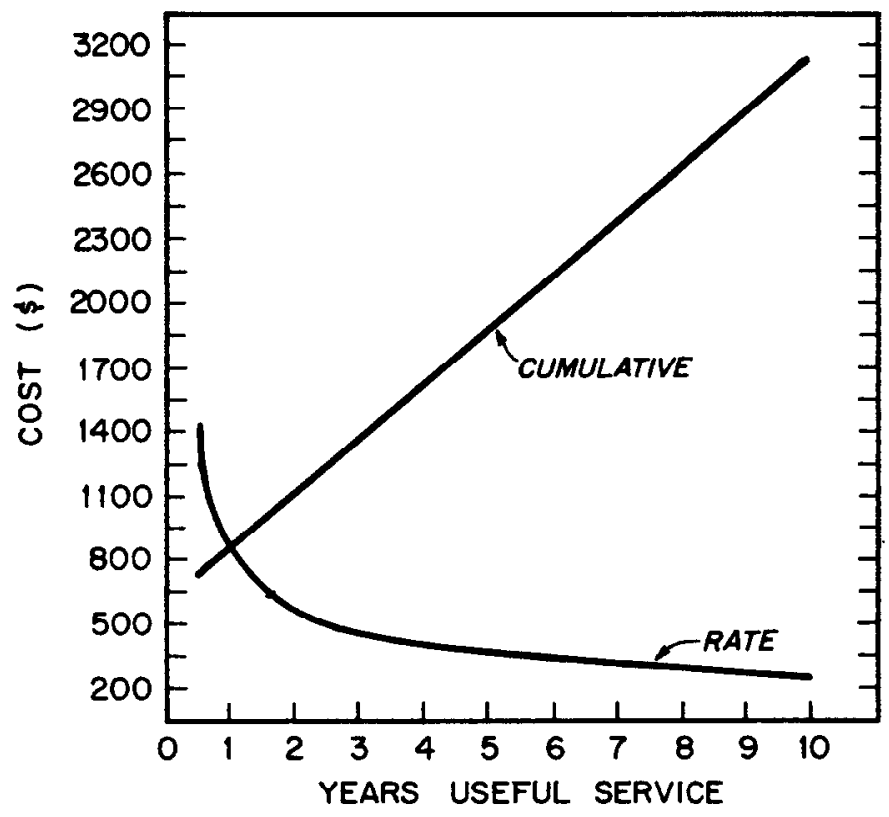

Fig. 2. Cost of livestock guarding dogs over time.
The cost per year decreases the longer a dog lives (Fig. 2), mainly because the purchase price is amortized over a longer period. Values for P of \$300 and for C of \$260 were based on McGrew and Andelt's (1985) study of 19 commercially-obtained dogs working in Kansas. For example, the cost of an 11 -year-old dog ( 10 effective years) is $\$ 3,160$; the average cost of those 10 working years is $\$ 316 /$ year. However, if a farm dog lives only 3 years, then the cost per working year rises to $\$ 540$. Ranch dogs living to only 18 months raise the cost per working year to $\$ 1,380$. Although the rancher hasn't actually paid out that many dollars, he would require 2 dogs to get 1 whole year's service. Thus, a producer who guards against accidents and spends time to train the dog achieves substantial savings.

Very few lambs have to be saved by a dog in order to justify a $\$ 300$ yearly cost. Perhaps 10 lambs or less per year would suffice, depending on the value of lambs. Many dogs have actually saved many more than this (Coppinger et al. 1983a, Green et al. 1984).

If Figure 1 represents a "normal" survivorship for livestock guarding dogs, a producer can use it to calculate the probability of his dog dying at any age. We emphasize that whenever a producer depends on dogs for protecting livestock, he or she needs a constant source of replacement animals. We also stress the importance of producers caring for their dogs. If all dogs lived to their 11 th birthday, then in every cohort of 1,000 dogs, the sheep industry would get 10,000 dog-years of service (subtracting the juvenile first year). Although ranchers on open range got only 2,300 dogs-years (23\% of the potential), farmers were getting 3,800 dog-years ( $38 \%$ of the potential). Good breeding stock, properly raised and protected from accidents, could increase these percentages.

\section{Literature Cited}

Beck, A. 1973. The Ecology of Stray Dogs. York Press, Baltimore.

Black, H.L. 1981. Navajo sheep and goat guarding dogs: a new world solution to the coyote problem. Rangelands 3:235-237.

Bronson, R.T. 1982. Variation in age at death of dogs of different sex and breeds. Amer. J. Vet. Res. 43:2057-2059.

Cairns, R.B. 1966. Development, maintenance, and extinction of social attachment behavior in sheep. J. Comp. \& Physiol. Psychol. 62:298-306.

Comfort, A. 1956. Longevity and mortality of Irish wolfhounds. Proc. Zool. Soc. London 127:27-34.

Comfort, A. 1960. Longevity and mortality in dogs of four breeds. J. Gerontology 15:126-129.

Coppinger, R., and L. Coppinger. 1980. So firm a friendship. Natural History 89:12-26 (March).

Coppinger, R., J. Lorenz, and L. Coppinger. 1983a. Introducing livestock guarding dogs to sheep and goat producers: p. 129-132 In: D.J. Decker, ed. Proc. First Eastern Wildl. Damage Control Conf., Cornell University, Ithaca.

Coppinger, R., J. Lorenz, J. Glendinning, and P. Pinardi. 1983b. Attentiveness of guarding dogs for reducing predation on sheep. J. Range Manage. 36:275-279.

Dixon, W.J., and M.B. Brown, eds. 1979. BMDP Biomedical Computer Programs. Univ. of Calif. Press, Berkeley.

Green, J.S., and R.A. Woodruff. 1983a. Guarding dogs protect sheep from predators. U.S. Dep. Agr. Info. Bull. No. 455.

Green, J.S., and R.A. Woodruff. 1983b. The use of Eurasian dogs to protect sheep from predators in North America: a summary of research at the U.S. Sheep Experiment Station: p. 119-124 In: D.J. Decker, ed. Proc. First Eastern Wildl. Damage Control Conf., Cornell University, Ithaca.

Green, J.S., R.A. Woodruff, and T.T. Tueller. 1984. Livestock guarding dogs for predator control: costs, benefits, and practicality. Wildlife Soc. Bull. 12:44-50.

McGrew, J.C., and W.F. Andelt. 1985. Livestock guarding dogs-a new method for reducing livestock losses. Kansas State Univ. Coop. Ext. Serv. MF 713, Manhattan Kans.

Muller-Schwarze, D., B. Stagge, and C. Muller-Schwarze. 1982. Play behavior: persistence, decrease, and energetic compensation during food shortage in deer fawns. Science 215:85-87.

Scott, J.P., and J.L. Fuller. 1965. Dog behavior. Univ. of Chicago Press, Chicago.

Tomlinson, K.A., and E.O. Price. 1980. Establishment and reversibility of species affinities in domestic sheep and goats. Animal Behavior 28:325-330. 